\title{
X-Ray Microanalysis of Boron Compounds: Approaches to Measuring Low-Z Materials
}

\author{
D. C. Meier ${ }^{*}$, J. M. Davis ${ }^{*}$, A. R. Konicek ${ }^{*}$, E. P. Vicenzi ${ }^{* *, *}$, and S. A. Wight ${ }^{*}$
}

* Surface and Microanalysis Science Division, Material Measurement Laboratory, National Institute of Standards and Technology, Gaithersburg, MD 20899-8371

** Museum Conservation Institute, Smithsonian Institution, Suitland, MD 20746

High-accuracy measurement of light elements is a challenging aspect of electron-probe microanalysis (EPMA). Soft X-rays $(<1 \mathrm{keV})$ emitted by low-Z elements present a variety of challenges, from their low X-ray yields to their high absorption cross sections in most heavier elements. Furthermore, the participation of valence electrons in the photoemission process complicates the peak shape and the concentration-dependent intensity. Despite these analytical difficulties, the broad academic interest in and the numerous industrial uses for materials rich in light elements make developing the best possible analytical methods for low-Z elements and to understand more precisely their measurement limitations a high research priority. This study focuses upon boron, which exhibits all of the above analytical challenges as well as broad chemical variety, whether in the form of borates, borides, boron hydrides, polymers, or covalent clusters.

One method for mitigating the limited signal expected from low- $\mathrm{Z}$ elements is to modify the instrumentation to capture a greater proportion of emitted soft X-rays. A variable-pressure scanning electron microscope equipped with a silicon drift detector (SDD) modified with the Lo-MAX optic (Parallax Research, Inc.) [1], which is designed to increase the effective solid angle for soft X-ray measurements, was used to perform measurements on a selection of boron-containing compounds. These energy-dispersive spectroscopy (EDS) measurements, when compared to identical ones made without the optic in place, exhibited a $50 \%$ reduction in error attributable to the instrument for boron measurements, as well as reductions in errors for other elements up to $Z=11$ (sodium) (Fig. 1).

We have recently completed an EPMA analysis of kernite $\left(\mathrm{Na}_{2} \mathrm{~B}_{4} \mathrm{O}_{6}(\mathrm{OH})_{2} \cdot 3 \mathrm{H}_{2} \mathrm{O}\right)$ [2], wherein selection and treatment of standards, time dependent intensities, and use of area-to-peak factors [3] were considered as methods for improving the quantitative analysis of this hydrated borate mineral. Notably, EPMA wavelength dispersive spectroscopy revealed variations in peak shape and in the relative intensity of non-diagram lines that appear to be dependent upon composition (Fig. 2). While earlier work attributes these satellites to multiple ionization events [4], there is apparently a significant dependence upon chemical environment. Molecular orbital calculations were performed to determine the extent to which chemical bonding could be correlated to peak shapes or the appearance and position of satellite peaks (Fig. 3).

\section{References}

[1] The full description of the procedures used in this abstract requires the identification of certain commercial products and their suppliers. The inclusion of such information should in no way be construed as indicating that such products or suppliers are endorsed by NIST or are recommended by NIST or that they are necessarily the best materials, instruments, software or suppliers for the purposes described. 
[2] D. C. Meier, J. M. Davis, and E. P. Vicenzi (2011). An examination of kernite $\left(\mathrm{Na}_{2} \mathrm{~B}_{4} \mathrm{O}_{6}(\mathrm{OH})_{2} \bullet\right.$ $3 \mathrm{H}_{2} \mathrm{O}$ ) using X-ray and electron spectroscopies: quantitative microanalysis of a hydrated low- $\mathrm{Z}$ mineral. Microsc. Microanal., in press.

[3] G. F. Bastin and H. J. M. Heijligers (2000). Quantitative electron probe microanalysis of boron. J. Solid State Chem. 154, 177-187.

[4] G. Rémond, R. Myklebust, M. Fialin, C. Nockolds, M. Phillips, and C. Roques-Carmes (2002). Decomposition of wavelength-dispersive X-ray spectra. J. Res. Natl. Inst. Stand. Technol. 107, 509529.

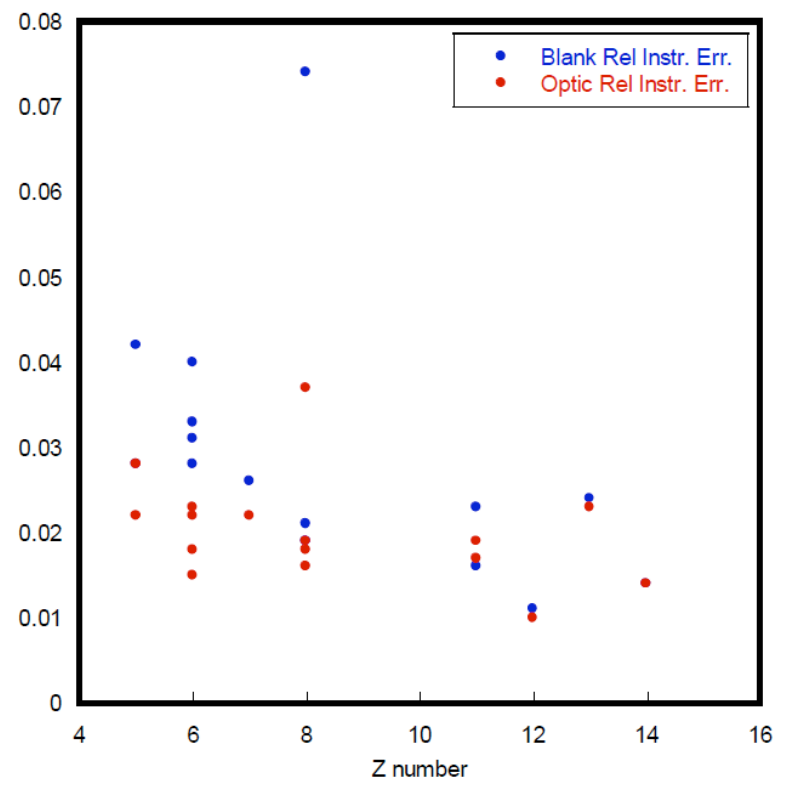

Fig. 1 (above). Relative measurement error in EDS for an SDD detector both with (red) and without (blue) the Lo-MAX optic installed for kernite, albite $\left(\mathrm{NaAlSiO}_{3}\right)$, cubic $\mathrm{BN}$, and $\mathrm{MgO}$. For elements lighter than sodium $(Z=11)$, measurement errors were observed to decrease.
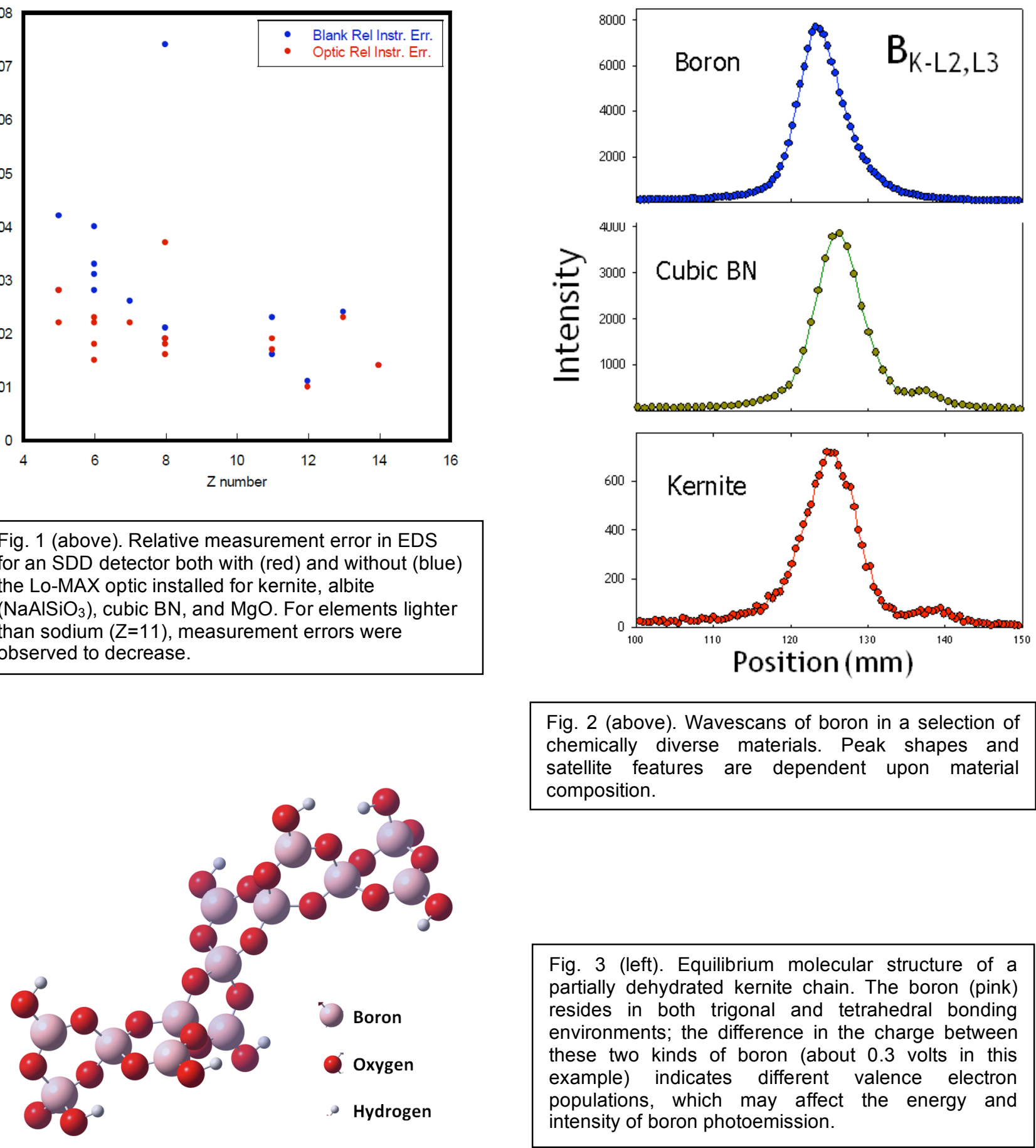

Fig. 2 (above). Wavescans of boron in a selection of chemically diverse materials. Peak shapes and satellite features are dependent upon material composition.

Fig. 3 (left). Equilibrium molecular structure of a partially dehydrated kernite chain. The boron (pink) resides in both trigonal and tetrahedral bonding environments; the difference in the charge between these two kinds of boron (about 0.3 volts in this example) indicates different valence electron populations, which may affect the energy and intensity of boron photoemission. 